\title{
A resistência, de Julián Fuks: uma narrativa de filiação
}

\author{
Resistance by Julián Fuks: A Filiation Narrative \\ La resistencia de Julián Fuks: una narrativa de filiación \\ Eurídice Figueiredo
}

\section{Resumo}

Neste artigo explorarei o conceito de "narrativa de filiação", de Dominique Viart, para analisar como Julián Fuks constrói sua relação com seus pais e irmãos e como as migrações dos ancestrais forjaram a família que veio parar em São Paulo durante a última ditadura militar na Argentina. Esse romance da era da pós-ficção aparece como testemunha do nosso tempo, testemunha dos horrores vivenciados por tantos humanos que perderam sua humanidade nos porões dos centros de tortura ou nos campos de extermínio durante a Segunda Guerra. Essa literatura de resistência se caracteriza pela ausência de linearidade, pela tensão entre o real e o ficcional, pela investigação, pelo recurso a hipóteses, plausíveis ou implausíveis, e pela preocupação com a questão social. Essa "escrita da restituição", nas palavras de Viart, coloca em dúvida suas próprias investigações e desconfia de discursos e conceitos, recusa as ideias prontas e as verdades bem estabelecidas. A postura enunciativa é explicitada e o leitor sabe quem fala e de que lugar fala o narrador.

Palavras-chave: literatura e ditadura, narrativa de filiação, pós-ficção, pós-memória.

\begin{abstract}
In this article I will explore Dominique Viart's concept of filiation narrative to analyze how Julián Fuks constructs his relationship with his parents and siblings, and how the migrations of his ancestors forged the family that ended up in São Paulo during Argentina's most recent military dictatorship. This novel of the post-fiction era seems to pay witness to our times, a witness to the horrors experienced by so many human beings who lost their lives in the dungeons of the torture centers or the extermination camps during the Second World. This literature of resistance is characterized by a lack of linearity, by the tension between the real and the fictional, by investigation, by the resort to hypotheses, whether plausible or implausible, and a concern with social issues. This "writing of restitution," to use Viart's words, casts doubt on its own investigations and is wary of discourses and concepts, rejects ready-made ideas and well-established truths. The enunciative posture is made explicit and the reader knows who is speaking and where the narrator is speaking from.
\end{abstract}

Keywords: literature and dictatorship, filiation narrative, post-fiction, post-memory.

\section{Resumen}

En el presente artículo exploraré el concepto de narrativa de filiación de Dominique Viart para analizar cómo Julián Fuks construye la relación con sus padres y hermanos y de qué modo las migraciones de los antepasados forjaron la familia que llegó a San Pablo durante la última dictadura militar en Argentina. Esta novela de la era de la post-ficción aparece como testigo de nuestro tiempo, testigo de los horrores experimentados por tantos humanos que han perdido su humanidad en los sótanos de los centros de tortura o en los campos de exterminio durante la Segunda Guerra Mundial. Dicha literatura de resistencia se caracteriza por la ausencia de linealidad, la tensión entre lo real y lo ficticio, la investigación, el uso de hipótesis, plausibles o inverosímiles, y la preocupación por el tema social. Esta "escritura de la restitución", según las palabras de Viart, pone en duda sus propias investigaciones $y$ sospecha de discursos y conceptos, rechaza ideas listas y verdades ya establecidas. La postura enunciativa queda explícita y el lector sabe quién habla y cuál es el lugar desde donde habla el narrador.

Palabras-clave: literatura y dictadura, narrativa de filiación, post-ficción, post-memoria.

\footnotetext{
* Universidade Federal Fluminense (UFF), Niterói, RJ, Brasil. (Dorcid.org/0000-0002-8265-3034. E-mail: euridicefig @gmail.com
} 
Ainda que o campo literário brasileiro seja bastante diferente do francês, vivemos hoje num mundo amplamente conectado, em que as obras circulam de forma vertiginosa, permitindo intenso intercâmbio dos modelos literários. Além disso, os desdobramentos históricos das duas guerras, da Shoá e das divisões do mundo como decorrência da guerra fria, repercutem aqui, guardadas as devidas proporções, de maneira similar. A especificidade da produção que busco analisar relaciona-se às tensões, às repercussões e aos prolongamentos do arbítrio das ditaduras sul-americanas, que provocaram a prisão, a morte, o desaparecimento e o exílio de milhares de pessoas. Neste artigo explorarei o conceito de narrativa de filiação de Dominique Viart, também retomado por Laurent Demanze, para analisar como Julián Fuks constrói sua relação com seus pais e irmãos e como as migrações dos ancestrais forjaram a família que veio parar em São Paulo durante a última ditadura militar na Argentina. A história familiar é caudatária da grande história.

Destaco a existência de pelo menos quatro escritores que poderíamos chamar de "filhos do exílio": além de Julián Fuks (já nascido em São Paulo), temos três autoras que vieram para cá ainda pequenas, Gabriela Aguerre (nascida no Uruguai), Paloma Vidal (nascida na Argentina) e Carola Saavedra (nascida no Chile). De algum modo, todos eles tematizam, em seus romances, questões que envolvem a relação com seus países de origem; no entrelugar em que se encontram, é comum o uso do espanhol em situações de diálogo, procedimento que causa algum estranhamento no ato de leitura. Viagens de caráter autobiográfico ou autoficcional rumo ao sul estão presentes em todos eles, com exceção de Carola Saavedra, que só menciona o Chile em O inventário das coisas ausentes (2014), um romance bastante áspero que mostra relações familiares conflituosas e violentas (o título talvez já indicie essa ausência no passado da autora). A primeira obra de Paloma Vidal intitula-se, significativamente, Mais ao Sul (2008), enquanto Gabriela Aguerre estreia com O quarto branco (2019), no qual a narradora-protagonista tem urgência de voltar ao Uruguai de sua infância. A menção às três autoras visa tão somente colocar Julián Fuks no contexto geopolítico do exílio de sua geração, pois não há espaço para analisar as obras delas no âmbito deste artigo.

Dominique Viart (Viart e Vercier, 2008) e Laurent Demanze (2008) perceberam a tendência de autores franceses, a partir dos anos 1980, de encenar suas origens, porque a transmissão da herança entrou em crise após as duas grandes guerras e, principalmente, devido às grandes transformações da sociedade, com o êxodo rural, o colapso de algumas profissões ou a mudança de classe social. Se na França ${ }^{1}$ essa narrativa de filiação tem suas implicações societais internas, na literatura brasileira esse tipo de romance é praticado, sobretudo, por autores descendentes de imigrantes, cujos laços familiares foram rompidos com viagens e choques culturais.

Viart (Viart e Vercier, 2008, p. 20) considera que o sucesso do aforismo do poeta René Char "Nossa herança nos é transmitida sem testamento" - exprime a consciência de uma herança em geral difícil de carregar e a necessidade de interrogar o passado, não para imitá-lo, nem para jogar com ele, mas para se conhecer através dele, numa espécie de diálogo que revitaliza curiosidades que certa modernidade tinha desfeito em proveito de sua prática da tabula rasa. Ele toma emprestado de Michel Chaillou a ideia de que o "extremo contemporâneo" põe todos os séculos juntos, ou seja, relê a biblioteca (basta pensar aqui na Biblioteca de Babel, de J. L. Borges) e, sem negar as rupturas da modernidade, leva em consideração as interrogações de toda a cultura acumulada.

Para Viart (Viart e Vercier, 2008, p. 79), a narrativa de filiação desloca a investigação da interioridade em favor da anterioridade, ou seja, o narrador faz uma prospecção da sua genealogia (ou de seus personagens) porque o conhecimento de si passa pela compreensão da vida do pai, da mãe ou dos avós. Do ponto de vista formal, caracteriza-se por um hibridismo genérico, já que dialoga tanto com a ficção quanto com a autobiografia; não é linear, procura recolher os fragmentos de uma herança e, para isso, precisa fazer uma busca, porquanto o narrador não conhece, senão de modo lacunar, aquilo que foi vivenciado pelos pais e avós. Em última instância, como a identidade se constrói através do outro, é preciso fazer reviver esse

\footnotetext{
${ }^{1}$ Os autores mais estudados nessa perspectiva na França são Claude Simon, Pierre Bergounioux, Gérard Macé, Pierre Michon e Annie Ernaux.
} 
outro do passado. Assim, a "narrativa de filiação, tomando a forma autobiográfica ou fictícia, é, pois, o modo privilegiado de escrita do sujeito" (Viart e Vercier, 2008, p. 92, tradução nossa). A narrativa de filiação se ancora numa ferida, entre testemunho travado e homenagem às figuras apagadas da ascendência.

Julián Fuks, que não sofreu diretamente nem os traumas da tortura nem a perseguição durante a ditadura, faz parte da segunda geração, aquela que herda o trauma familiar e possui o que Marianne Hirsch (2008) chamou de pós-memória, que designa a memória de eventos vividos pelos ancestrais, transmitida através do testemunho pessoal de familiares ou amigos. $\mathrm{E}$ é também difícil relatar aquilo que não se viveu, aquilo que está saturado de não ditos, de segredos de família, de fatos envoltos na bruma de um passado que não passa, apesar de todos os esforços para esquecê-lo. Trata-se de um ato de transferência inter e transgeracional da "geração-dobradiça" (Hoffman apud Hirsch, 2008, p. 103, tradução nossa), porque une aqueles que vivenciaram a guerra (ou a ditadura) e as novas gerações.

No romance A resistência, o narrador refaz os percursos de sua família materna, católica, espanhola, e de sua família paterna cuja origem remonta à Alemanha, de onde provém o sobrenome. Parte da família foi para a Romênia, adaptando a grafia ao novo idioma. O avô Abraham e sua esposa Ileana, ambos judeus, temendo o antissemitismo crescente, decidiram migrar para a Argentina nos anos 1920, onde nasceria o pai de Julián nos anos 1940, no momento em que os judeus eram mandados para os campos da morte. Se o pai sabia, vagamente, que os avós tinham sido deportados, esse assunto não era tratado nas reuniões da família. Não se falava disso de um ponto de vista pessoal, senão como assunto histórico, portanto, impessoal. E Fuks declara numa entrevista que o pai, incentivado pelo seu romance, "subjetivou o seu passado, foi atrás dessa trajetória pessoal que ilustra e representa uma coisa mais ampla, mais social, mais histórica e mais política" (Fuks, 2018, p. 276). Trata-se, segundo ele, de um corte geracional, destacando justamente a tendência contemporânea de criar narrativas de filiação, "de recuperação das próprias raízes, da procura desses fantasmas [...], a procura desses traumas que ficaram, em alguma medida, relegados ao passado, mas que reverberam constantemente na nossa existência" (Fuks, 2018, p. 276).

Em $A$ resistência, de Julián Fuks, que se apresenta como romance, a ficção consiste muito mais no arranjo da linguagem a fim de dar uma forma estética que possa entrar em comunicação com o leitor do que, propriamente, como fantasia, imaginação ou fabulação. $\mathrm{O}$ escritor não pode restituir a verdade plena do acontecimento, isso não é realizável, como já escrevia Walter Benjamin (1993, p. 224): "Articular historicamente o passado não significa conhecê-lo 'como ele de fato foi'. Significa apropriar-se de uma reminiscência, tal como ela relampeja no momento de um perigo". E Fuks observa que, mesmo diante da materialidade que evoca o passado, como a casa onde algo aconteceu, o local da catástrofe, não é possível ter acesso à verdade: "Por isso, o tipo de literatura ou autoficção que mais me interessa hoje é a que desconfia de si mesma e desconfia da própria capacidade de reconstruir o passado" (Fuks, 2018, p. 277).

Um artigo do próprio Julián Fuks, "A era da pós-ficção", publicado no livro coletivo Ética e pósverdade, pode ajudar a compreender a questão. Ele assinala a imposição ética em que se encontra e que o leva a enredos verdadeiros, como é o caso de seu romance $A$ resistência, de modo que a verdade no romance passa a ocupar uma centralidade impensada há um século. Dessa maneira, são suas próprias biografias, suas lembranças e seus passados que exploram os escritores atuais, "seres estranhos, deslocados, perdidos", "ficcionistas na era da pós-ficção" (Fuks, 2017, p. 76).

Romance e testemunho se fundem ou se confundem como poucas outras vezes. O romance se faz um gênero híbrido, se aproxima do ensaio, da reportagem, da autobiografia, do relato historiográfico, dessas outras formas que já lhe pertenciam, mas assemelhando-se a elas como em nenhum outro tempo (Fuks, 2017, p. 82).

Nesse movimento atual, curiosamente ressurge a velha questão da verdade, muito presente no romance do século XVIII, quando o autor fazia prólogos e notas do editor para assegurar a veracidade da história que narrava, usando artifícios tais como: originais encontrados por acaso ou entregues pelo próprio protagonista, palavras apagadas ou incompreensíveis, rasuras. Mas a 
questão que retorna já se encontra transformada, porque agora o narrador/autor não é confiável, ele duvida de si mesmo, duvida da plausibilidade daquilo que relata. Assim, Fuks vê um movimento em espiral na história do gênero, "uma espiral ainda capaz de provocar alguma vertigem" (Fuks, 2017, p. 90). E apesar de muitos anúncios de sua morte, o romance resiste justamente porque é um gênero aberto, que se apropria de procedimentos de outros gêneros e, por isso, está em constante mutação. Isso comprova a ideia exposta por Viart de que a literatura contemporânea não se caracteriza pela ruptura, pela "tábula rasa", ao contrário, ela relê a biblioteca, relê a tradição, com claras inovações, porém.

O escritor que lida com a verdade está numa corda bamba, pois, a despeito de querer revelar a verdade, ele tem de fabular para compor cenários, dar sentido para os vestígios deixados pelo passado. Desse modo, seu empreendimento é sempre sentido como um fracasso:

Sei que escrevo meu fracasso. Não sei bem o que escrevo. Vacilo entre um apego incompreensível à realidade - ou aos esparsos despojos de mundo que costumamos chamar de realidade - e uma inexorável disposição fabular, um truque alternativo, a vontade de forjar sentidos que a vida se recusa a dar (Fuks, 2015, p. 95).

Esse romance da era da pós-ficção aparece como testemunha do nosso tempo, testemunha dos horrores vivenciados por tantos humanos que perderam sua humanidade nos porões dos centros de tortura ou nos campos de extermínio durante a Segunda Guerra. É nesse contexto que o romance se reinventa e se mostra fragmentário, lacunar, um puzzle em que faltam peças, em que enigmas não são resolvidos de maneira a tranquilizar o leitor.

Dominique Viart (Viart e Vercier, 2008, p. 12) postula que, diferentemente da literatura consentante, que quer agradar e fazer sucesso e, para isso, consente em fazer concessões ao gosto do público, existe a literatura déconcertante, que se concebe como atividade crítica e que chega onde não se espera que chegue. A literatura que tematiza os horrores não pode aplacar, acalmar, apaziguar as consciências; ela deve, ao contrário, desconcertar, provocar o mal-estar e a inquietação. É por essa razão que a melancolia dá o tom, o sentimento de derrota predomina, a incompletude solapa as falácias das soluções fáceis. Essa literatura de resistência se caracteriza pela ausência de linearidade, pela tensão entre o real e o ficcional, pela investigação (que toma, às vezes o ar de narrativa policial), pelo recurso a hipóteses, plausíveis ou implausíveis, e a preocupação com a questão social. Essa "escrita da restituição", nas palavras de Viart, coloca em dúvida suas próprias investigações e desconfia de discursos e conceitos, recusa as ideias prontas e as verdades bem estabelecidas. A postura enunciativa é explicitada e o leitor sabe quem fala e de que lugar fala o narrador.

Fuks reflete sobre o papel desse tipo de literatura nos dias de hoje ao afirmar que escrever, para ele, é se reposicionar, reelaborar e se redimir. "A literatura se faz nessa busca. Há em certa medida uma dívida com o passado que a literatura não vai saldar, mas ela possibilita a compreensão desse passado" (Fuks, 2018, p. 284). Nesse sentido, a literatura se aproxima da psicanálise: ao encontrar palavras e sentidos, já adquire um papel transformador.

Laurent Demanze (2008, p. 22) detecta uma preocupação arqueológica do escritor contemporâneo que, ao perscrutar os resquícios do passado, vê revelada uma parte desconhecida de si e, nesse sentido, faz uma "retrospecção hermenêutica". Ele também aponta para a necessidade de exumação de vestígios de uma herança em frangalhos, difícil de ser transmitida: "É no espelho do outro que o indivíduo contemporâneo se descobre, ao elaborar uma narrativa em que a ficção se mistura às lembranças e a escrita de si à fábula familiar" (2008, p. 9, tradução nossa).

Sobre a questão do exílio e da transmissão dos traumas familiares o narrador pergunta: "Pode um exílio ser herdado? Seríamos nós, os pequenos, tão expatriados quanto nossos pais? Devíamos nos considerar argentinos privados do nosso país, da nossa pátria? Estará também a perseguição política submetida às normas da hereditariedade?” (Fuks, 2015, p. 19). E nessa pergunta fica explicitado que o sujeito recebe uma herança dos pais e avós que molda sua personalidade: cabe a ele descobrir como assumi-la ou rejeitá-la.

O romance atual, como $A$ resistência, não se restringe a contar uma história, ele quer interpretar o homem e o mundo, torna-se híbrido e autocrítico. E o escritor, encarnando o 
sujeito em crise, questiona a própria linguagem, sempre inadequada, precária, para dizer realidades complicadas, sentimentos e afetos convulsionados. No primeiro capítulo é a palavra "adotado" que é colocada em xeque: como falar do irmão sem ferir suscetibilidades? Como falar do outro, de um outro que já tem suas cicatrizes? Como não feri-lo de novo? Como reconstituir uma vida de carne e sangue por palavras desgastadas pelo uso cotidiano?

Apesar de a ideia inicial ter sido a de contar a história do irmão adotado, a quem o romance é dedicado, ele narra a história da família no contexto da ditadura e do exílio. A epígrafe é uma frase do escritor argentino Ernesto Sabato, que diz: "Creo que hay que resistir: éste ha sido mi lema. Pero hoy, cuántas veces me he preguntado cómo encarnar esta palabra". A palavra resistência é usada com vários sentidos e em vários contextos nesse romance, mas quero destacar o principal deles, o sentido político, já que os pais, psicanalistas, quiçá militantes, deixaram a Argentina durante a ditadura militar. O autor, nascido em São Paulo em 1981, coloca-se como herdeiro desse exílio e desse trauma. Os pais resistiram porque não aceitaram as novas regras que impunham o terror, a falta de liberdade, a perseguição àqueles que ousaram discordar. Valentín Baremblitt, o diretor do hospital onde a mãe trabalhava, fora preso e torturado enquanto Marta Brea, sua amiga e colega de trabalho, havia desaparecido; já o consultório do pai tinha sido sistematicamente destruído; ou seja, para os pais, o cerco se fechava a tal ponto que só lhes restava partir rumo ao exílio. Baremblitt, na prisão, diz à mãe do narrador: "Vocês têm que sair, vocês são os próximos" (Fuks, 2015, p. 81).

Trata-se de um momento crucial na vida de qualquer pessoa, sobretudo para os militantes que tiveram de abandonar a luta para não perder a vida. Esse questionamento lateja naqueles momentos agônicos em que a derrota fica clara, em que os companheiros estão presos, mortos ou desaparecidos. Esse travo de incerteza frente à consciência põe em dúvida se fugir é trair a luta:

Resistir: quanto em resistir é aceitar impávido a desgraça, transigir com a destruição cotidiana, tolerar a ruína dos próximos? Resistir será aguentar em pé a queda dos outros, e até quando, até que as pernas próprias desabem? Resistir será lutar apesar da óbvia derrota, gritar apesar da rouquidão da voz, agir apesar da rouquidão da vontade? É preciso aprender a resistir, mas resistir nunca será se entregar a uma sorte já lançada, nunca será se curvar a um futuro inevitável. Quanto do aprender a resistir não será aprender a perguntar-se? (Fuks, 2015, p. 79).

O momento de partida rumo ao exílio configura essa tomada de posição atormentada em que o sujeito parece abandonar a causa, ainda que saiba que precisa salvar sua vida, que sua morte de nada servirá diante da derrota que se afigura no horizonte. Esse ponto de inflexão na resistência aparece em muitos relatos e romances que tratam da ditadura brasileira: Azul corvo, de Adriana Lisboa; Ainda estou aqui, de Marcelo Rubens Paiva; K. Relato de uma busca, de B. Kucinski; Os carbonários, de Alfredo Sirkis. Partir para o exílio é também resistir, resistir a se submeter à prisão e à morte.

Assim, abruptamente, os pais, com o bebê adotado, então com 6 meses de vida, deixam Buenos Aires, atravessam de carro a fronteira com o Uruguai, tomam o avião para São Paulo: "Partir e esquecer a derrota, partir e esquivar o descalabro, e preservar o que lhes restava, fosse muito ou fosse pouco, a existência diária que a cada dia lhes roubavam" (Fuks, 2015, p. 82). Em São Paulo começaria uma nova vida, uma vida de exílio, uma adaptação lenta aos costumes do país, situação dúbia em que se está em dois lugares ao mesmo tempo, porque o país natal não nos deixa nunca, nós o carregamos como o caracol carrega a sua casa.

O escritor problematiza seu fazer literário porque necessita de novas formas de urdir a trama romanesca; ele relê a tradição literária a fim de dar conta de uma situação fronteiriça entre dizer a verdade e criar ficção. Esse aspecto autoficcional fica muito claro no capítulo 46 de $A$ resistência, em que se encena a discussão entre os pais e o escritor, depois do livro acabado e lido por eles: "É estranho, minha mãe diz, você diz mãe e eu vejo meu rosto, você diz que eu digo e eu ouço minha voz, mas logo o rosto se transforma e a voz se distorce, logo não me identifico mais. Não sei se essa mulher sou eu, me sinto e não me sinto representada, não sei se esses pais somos nós" (Fuks, 2015, p. 135). A conversa desvela, por exemplo, a inversão do problema com comida do irmão que aparece magro demais no romance quando, na realidade, ele tem sobrepeso. O pai parece mais reticente do que a mãe, acha que foi retratado como um militante 
ingênuo, que guardava armas debaixo da cama, que participou de uma reunião absurda no Parque da Água Branca, em São Paulo, mas, afinal, ele conclui: "Aqueles eram mesmo anos inverossímeis" (Fuks, 2015, p. 136). O pai exprime temor ao tornar público o íntimo e, ao mesmo tempo, carinho pelo filho que contou a história da família. Não quer reprimir o filho, impedi-lo de fazer seu trabalho e publicar seu livro, por isso suas últimas palavras são: "Só não quero que você se guie pelo que digo, isso eu jamais quis: vá em frente, Sebastián, você fez o que tinha que fazer, e até é possível que alguém leia nisto um bom romance" (Fuks, 2015, p. 137).

É só nesse momento que o narrador recebe um nome, Sebastián, o mesmo que ele tinha no romance precedente, Procura do romance (Fuks, 2011), nome com a mesma terminação de Julián. Esse personagem perambula pelas ruas de Buenos Aires, reflete sobre o romance que quer escrever, mas reflete, sobretudo, sobre a família que teve de deixar a cidade, rememora os anos que passou na infância em Buenos Aires, quando os pais decidiram voltar, após o fim da ditadura.

O exercício memorial e escritural empreendido por Julián Fuks aponta para a atitude de resistência, de combate a todo autoritarismo e a toda violência fascista que afetaram a vida de seus pais. Seu livro é um alerta para novas formas de repressão que nos ameaçam a cada dia pois, como diz o narrador de Fuks, as "ditaduras podem voltar [...], seus arbítrios, suas opressões, seus sofrimentos, existem das mais diversas maneiras, nos mais diversos regimes, mesmo quando uma horda de cidadãos marcha às urnas bienalmente" (Fuks, 2015, p. 40). Alfredo Bosi afirma que o sentido mais profundo do verbo resistir "apela para a força da vontade que resiste a uma outra força, exterior ao sujeito. Resistir é opor a força própria à força alheia" (1996, p. 11). A resistência é um conceito ético, mas pode se tornar um conceito estético "quando o narrador se põe a explorar uma força catalisadora da vida em sociedade: os seus valores" (1996, p. 13). Os escritores, inseridos na sociedade num dado momento histórico, mais ou menos afetados pelos horrores cometidos por regimes de exceção, são levados a testemunhar suas experiências ou as de seus familiares. Este é o caso do escritor Julián Fuks, autor de A resistência (2015).

O escritor narra um passado de antes do seu nascimento, um passado que não conhece nem pode compreender, por conseguinte, ele se apoia no que lhe foi contado, em cacos de informação, muito mais dúvidas do que certezas: "Isto é história e, no entanto, quase tudo o que tenho ao meu dispor é a memória, noções fugazes de dias tão remotos, impressões anteriores à consciência e à linguagem, resquícios indigentes que eu insisto em malversar em palavras" (Fuks, 2015, p. 23).

O romance A resistência (2015) é emblemático desse deslizamento genérico que acontece nesse início de século e que torna o narrador do romance autoconsciente e autocrítico, hesitando entre dizer uma verdade que o atormenta e a necessidade de ficcionalizar o vivido, ainda que isso o leve a vacilar ainda mais. Perscrutando a história familiar, atingida pela violência da ditadura militar argentina, o narrador faz o luto e tenta costurar os vestígios deixados a fim de dar uma coerência que a vida parece não lhes ter oferecido.

Nesse mundo de incertezas, usando uma memória fugidia, vicária, que não lhes pertence de todo, escritores como Fuks fazem uso de fotografias do passado, tentando interpretar olhares, sorrisos, paisagens. A fotografia representa um real que passou, como já afirmou Roland Barthes (1984) em sua famosa frase de A câmara clara: "Isso foi". Philippe Dubois (1993, p. 50) esclarece que a capacidade de representação da fotografia se deve a seu caráter indiciário, tomando emprestada a noção de índice de Charles S. Peirce, ou seja, estabelece uma relação de conexão física com o referente no momento de sua produção. Na recepção, entretanto, a interpretação da fotografia depende de quem a olha, se conheceu a pessoa, se sabe em que condições a fotografia foi realizada ou não. A foto de sua mãe que emociona Barthes - ela menina no jardim de inverno -, de que fala de modo compungido, não é mostrada no livro porque ninguém seria sensível a ela da mesma maneira que ele foi. No exercício que Barthes faz de olhar as fotos da mãe, ele tenta achar aquilo que punge, que ele chamou de punctum. Assim, o sentido da fotografia lhe é exterior (Dubois, 1993, p. 52).

Desse modo, as fotografias não esclarecem nada, os chamados instantâneos capturam um momento, um momento que passou. No fundo, as fotografias mentem, porque elas são as provas de um mundo desaparecido, de um mundo em ruínas, de pessoas em sua infância ou juventude, hoje já velhas ou mortas. Em outras palavras, olhar as fotografias é falar com 
fantasmas, é testemunhar a presença da ausência. Fuks olha os retratos de família tentando capturar sentido em gestos, olhares, sorrisos. Para além dos elementos presentes na fotografia, o que conta é o gesto interpretativo de quem olha, é ele que atribui sentido e sentimento a imagens que, para outros, talvez não signifiquem nada.

O narrador analisa cinco fotos do irmão. Na primeira, ao olhar aquele menino, aparentemente sozinho na varanda, com seus olhos claros e sua beleza infantil, cogita que não pode fazer dele um personagem frágil. A principal questão diz respeito à ausência de voz do irmão: "Estarei com este livro tratando de lhe roubar a vida, de lhe roubar a imagem, e de lhe roubar também, furtos menores, o silêncio e a voz?" (Fuks, 2015, p. 25). Na verdade, o irmão não é objetificado, não está totalmente mudo na narrativa; sua voz se faz presente principalmente no capítulo 42 , o clímax do romance, quando se dá sua explosão em meio à crise familiar. O irmão verbaliza sua solidão, o vazio em que vive, seu medo e sua dor. É neste momento que pede ao autor que escreva sobre ser adotado.

Examinando outra fotografia do álbum de família, o narrador tenta buscar sentidos numa narrativa imaginária a fim de fazer reviver a cena do passado, mas sente-se frustrado porque a foto é muda ao passo que ele insiste em "traduzir sua retórica, em captar sua tortuosa sentença" (Fuks, 2015, p. 65). Da mesma forma que a escritora francesa Annie Ernaux, cujo romance Os anos, recentemente traduzido no Brasil, parte de fotos de família para reconstituir sua história familiar e, ao mesmo tempo, a parcela da história da França que lhe coube viver, Fuks tenta desvendar a história dos seus a partir de fotos. Para Ernaux (2014, p. 73) elas funcionam como detonadores de lembranças e, por conseguinte, de escrita, situando-se, porém, mais do lado da morte que do lado da vida. As fotos correspondem ao tempo parado.

A foto mais emblemática é, talvez, aquela que mostra a mãe montando o álbum, construindo a memória familiar que o autor transforma em palavras no livro. Ao reconstituir a história dos pais, ao tentar entender os dramas do irmão adotivo, ele se dá conta que é parte dessa história: "Ao vêlos, sinto que sou em parte um ser que eles moldaram para contá-los, que minha memória é feita de sua memória, e minha história haverá sempre de conter a sua história" (Fuks, 2015, p. 104).

Assim, fica confirmada mais uma vez a relevância da categoria "narrativa de filiação" para analisar esse tipo de romance. A resistência possui os quatro elementos decisivos nos termos traçados por Dominique Viart: o narrador faz o desvio pela história do irmão e dos pais para poder voltar a si, para se compreender como parte dessa herança; de gênero híbrido, o livro não tem nem o formato do romance nem da autobiografia tradicional; a narrativa não é linear, ela recolhe fragmentos significativos a fim de deslindar os fios da história, investigando hipóteses de explicação, mesmo as mais descabidas, como conjecturar sobre a possibilidade de o irmão ser filho de uma das presas políticas assassinadas na Argentina; e, finalmente, questiona o uso da língua e reflete sobre a linguagem adequada a ser utilizada.

A narrativa de filiação traduz uma necessidade de nossa época. E, como em outros períodos da história, o romance reflete sobre si mesmo, sobre a crise da escrita, sobre a perda de referências e o abalo dos valores humanistas devido ao fracasso das ideologias do progresso. O narrador dessas narrativas duvida de si mesmo, interroga os ancestrais e questiona a herança. O presente no Brasil, que deveria ser o resultado feliz da luta dos pais contra as ditaduras do passado, é ameaçador e decepcionante. A literatura desconcertante transfigura essas hesitações, insiste em ver os lampejos dos vagalumes que, apesar das luzes ofuscantes dos fascismos, não desapareceram - nas palavras de Didi-Huberman (2014, p. 160): “Alguns estão bem perto de nós, eles nos roçam na escuridão; outros partiram para além do horizonte, tentando reformar em outro lugar sua comunidade, sua minoria, seu desejo partilhado". A literatura de Julián Fuks é de resistência.

\section{Referências}

BARTHES, Roland (1984). A câmara clara: notas sobre a fotografia. Tradução de Júlio Castañon Guimarães. Rio de Janeiro: Editora Nova Fronteira. 
BENJAMIN, Walter (1993). Sobre o conceito de história. In: BENJAMIN, Walter. Obras escolhidas: magia e técnica, arte e política. Tradução de Sérgio Paulo Rouanet. v. 1. São Paulo: Brasiliense. p. 222-232.

BOSI, Alfredo (1996). Narrativa e resistência. Itinerários. Araraquara, n. 10, p. 11-27. Disponível em: https:// bit.ly/3aV4Nvu. Acesso em: 21 jan. 2020.

DEMANZE, Laurent (2008). Encres orphelines: Pierre Bergounioux, Gérard Macé, Pierre Michon. Paris: José Corti.

DIDI-HUBERMAN, Georges (2014). Sobrevivência dos vaga-lumes. Tradução de Vera Casa Nova e Márcia Arbex. Revisão de Consuelo Salomé. Belo Horizonte: Editora da UFMG.

DUBOIS, Philippe (1993). O ato fotográfico e outros ensaios. Tradução de Marina Appenzeller. Campinas, SP: Papirus Editora.

ERNAUX, Annie (2014). Le vrai lieu: entretiens avec Michelle Porte. Paris: Gallimard.

FUKS, Julián (2011). Procura do romance. Rio de Janeiro: Record.

FUKS, Julián (2015). A resistência. São Paulo: Companhia das Letras.

FUKS, Julián (2017). A era da pós-ficção: notas sobre a insuficiência da fabulação no romance contemporâneo. In: DUNKER, Christian et al. Ética e pós-verdade. Porto Alegre: Dublinense, p. 73-93.

FUKS, Julián (2018). A situação da narrativa contemporânea hoje. [Entrevista concedida a] Felício Laurindo Dias. Soletras, Rio de Janeiro, n. 36, p. 273-285, jul/dez. Disponível em: https://bit.ly/2O3yx0r. Acesso em: 20 set. 2019.

HIRSCH, Marianne (2008). The generation of postmemory. Poetics Today. Durkham, n. 29, p. 103-128, mar. Disponível em: https://bit.ly/2wX5bLq. Acesso em: 13 nov. 2012.

VIART, Dominique; VERCIER, Bruno (2008). La littérature française au présent: héritage, modernité, mutations. Paris: Bordas. 